\title{
Association between Cardio-ankle Vascular Index and Contrast-induced Nephropathy
}

\author{
Salih Sahinkus ${ }^{1}$, Ercan Aydin ${ }^{2}$, Muhammet Necati Murat Aksoy ${ }^{1}$, Cağla Akcay ${ }^{1}$, Emre Eynel ${ }^{1}$ and Selcuk Yaylaci $^{3}$ \\ ${ }^{1}$ Department of Cardiology, Sakarya University Education and Research Hospital, Turkey \\ ${ }^{2}$ Department of Cardiology, Vakfikebir State Hospital, Turkey \\ ${ }^{3}$ Department of Internal Medicine, Sakarya University Education and Research Hospital, Turkey
}

\begin{abstract}
Objective: To investigate the relationship between cardio-ankle vascular index (CAVI), which is a marker of arteriosclerosis and the development of contrast-induced nephropathy (CIN).

Study Design: Descriptive study.

Place and Duration of Study: Department of Cardiology, Sakarya University Medical Faculty, from May to December 2019.

Methodology: Between May and December 2019, demographic characteristics, CAVI measurements, and in-hospital clinical outcomes were compared among 66 patients, who developed CIN after coronary angiography (CAG) and an acute coronary syndrome (ACS) diagnosis, and 60 ACS patients without CIN.

Results: The frequency of CIN development in the study was 5.5\%. In the CIN group, EF was lower $(44.5 \pm 10.6 \%$ vs. $49.3 \pm$ $9.8 \%, \mathrm{p}=0.011)$ and GFR $\left(\mathrm{mL} / \mathrm{min} / 1.73 \mathrm{~m}^{2}\right)$ at admission, was lower $(60.3 \pm 23.3 \mathrm{vs} .87 .0 \pm 21.5, \mathrm{p}<0.001)$ than in the nonCIN group. CAVI values indicative of arterial stiffness (AS) were significantly higher in the CIN group. Mortality was not significantly higher in the CIN group ( $p=0.099)$.

Conclusion: AS is more common in ACS patients, who developed CIN after CAG. Older patients with low EF and low GFR, in whom AS is more common, should be intravenously hydrated and more closely monitored to prevent CIN development.
\end{abstract}

Key Words: Contrast-induced nephropathy, Acute coronary syndrome, Cardio-ankle vascular index, Arterial stiffness.

How to cite this article: Sahinkus S, Aydin E, Aksoy MNM, Akcay C, Eynel E, Yaylaci S. Association between Cardio-ankle Vascular Index and Contrast-induced Nephropathy. J Coll Physicians Surg Pak 2020; 30(12):1251-1255.

\section{INTRODUCTION}

Cardio-ankle vascular index (CAVI) measures aorta-femoral-tibial arterial stiffness (AS) independent of blood pressure. ${ }^{1}$ CAVI correlates with age and has been reported to have higher values in patients with atherosclerotic heart disease. ${ }^{2}$ According to the manufacturer's instructions, a CAVI less than 8.0 is supposed to be normal; whereas, a value less than 9.0 but more than (orequal to) 8.0 is considered borderline. At the other end of the spectrum,

a CAVI equal or more than 9.0 leads to the diagnosis of suspected arteriosclerosis. ${ }^{3}$ It has been shown that carotid intima-media thickness, one of the markers of severe coronary artery disease (CAD), is significantly associated with CAVI. ${ }^{2}$ These studies suggest that CAVI is effective, can be applied simply, and can also be used as a predictor ofCAD in the future.

Correspondence to: Dr. Salih Şahinkuş, Department of Cardiology, Sakarya University Education and Research Hospital, Turkey

E-mail: drsalihsahinkus@gmail.com

Received: July 28, 2020; Revised: November 08, 2020;

Accepted: December 08, 2020

DOI: https://doi.org/10.29271/jcpsp.2020.12.1251
Although there are no standard criteria, the most commonly used definition for contrast-induced nephropathy (CIN) is an increase of the basal serum creatinine ( $\mathrm{s} C \mathrm{Cr}$ ) levels by $25-50 \%$ or $0.5 \mathrm{mg} / \mathrm{dL}$ within $48-72$ hours after contrast agent exposure. ${ }^{4}$ Vasoconstriction, reactive oxygen species (ROS) and renal ischemia are the main mechanisms in CIN pathophysiology. There is no specific treatment for $\mathrm{CIN}$, the main recommended treatment is considered to be preventing the development of CIN.

The aim of this study was to investigate the relationship between CAVI, which is a marker of arteriosclerosis, and the development of CIN.

\section{METHODOLOGY}

Between May and December 2019 at Department of Cardiology, Sakarya University Medical Faculty, among the 1,520 patients who underwent CAG for acute coronary syndrome (ACS), 66 patients were identified with developed CIN due to the contrast agent used in angiography. 60 non-CIN patients were randomly selected. Baseline characteristics and clinical history of the patients; angiography procedure characteristics; blood pressure values at the time of admission to coronary care unit (CCU); urea / creatinine/glomerularfiltration rate(GFR) valuestakenatadmission and after 48-72 hours; and CAVI/ABI values were recorded. 
Table I: Baseline and clinical characteristics.

\begin{tabular}{|c|c|c|c|}
\hline & $\begin{array}{c}\text { CIN group, } \\
\mathrm{n}=66(52.4 \%)\end{array}$ & $\begin{array}{l}\text { Non-CIN group, } \\
n=60(47.6 \%)\end{array}$ & $\mathbf{p}$ \\
\hline Age, years & $69.9 \pm 11.8$ & $62.1 \pm 11.9$ & $<0.001$ \\
\hline $\begin{array}{l}\text { Sex, n (\%) } \\
\text { Male } \\
\text { Female }\end{array}$ & $\begin{array}{l}37(56.1) \\
29(43.9)\end{array}$ & $\begin{array}{l}33(55.0) \\
27(45.0)\end{array}$ & 0.905 \\
\hline $\mathrm{BMI}, \mathrm{kg} / \mathrm{m}^{2}$ & $27.7 \pm 4.2$ & $27.7 \pm 3.3$ & 0.993 \\
\hline Hypertension, n (\%) & $46(69.7)$ & $36(60.0)$ & 0.254 \\
\hline Diabetes mellitus, n (\%) & $34(51.5)$ & $20(33.3)$ & 0.039 \\
\hline Hyperlipidemia, n (\%) & $5(7.6)$ & $3(5.0)$ & 0.720 \\
\hline Prior MI, n (\%) & $22(33.3)$ & $19(31.7)$ & 0.842 \\
\hline Prior stent, n (\%) & $10(15.2)$ & $13(21.7)$ & 0.344 \\
\hline Prior CABG, $\mathrm{n}(\%)$ & $8(12.1)$ & $1(1.7)$ & 0.034 \\
\hline Current smoker, n (\%) & $18(27.3)$ & $26(43.3)$ & 0.059 \\
\hline Postrenal disease, n (\%) & $2(3.0)$ & $1(1.7)$ & $>0.999$ \\
\hline Current urinary stone, $\mathrm{n}(\%)$ & $0(0.0)$ & $1(1.7)$ & 0.476 \\
\hline Systolic blood pressure, $\mathrm{mmHg}$ & $134.8 \pm 28.6$ & $124.8 \pm 45.9$ & 0.142 \\
\hline Diastolic blood pressure, $\mathrm{mmHg}$ & $75.6 \pm 15.6$ & $72.4 \pm 26.2$ & 0.407 \\
\hline$E F, \%$ & $44.5 \pm 10.6$ & $49.3 \pm 9.8$ & 0.011 \\
\hline ACE inhibitors, n (\%) & $51(77.3)$ & $50(83.3)$ & 0.394 \\
\hline Statins, $\mathrm{n}(\%)$ & $66(100.0)$ & $57(95.0)$ & 0.105 \\
\hline I.v. saline, n (\%) & $29(43.9)$ & $4(6.7)$ & $<0.001$ \\
\hline I.v. nitrate infusion, n (\%) & $13(19.7)$ & $7(11.7)$ & 0.218 \\
\hline
\end{tabular}

These values and in-hospital outcomes of the two groups were compared. Patients with cardiogenic shock, Killip II-III pulmonary edema, any life-threatening major bleeding, peripheral arterial disease (PAD), an ankle-brachial index (ABI) below 0.9, and a GFR / $1.73 \mathrm{~m}^{2}$ value under 30 were excluded. Estimated GFR was derieved by the modification of diet in renal disease (MDRD) equation: $0.741 \times 175 \times$ $\mathrm{Cr}^{-1.154} \times$ age $^{-0.203}$ ( $x 0.742$, if female).

It is defined that $\mathrm{CIN}$ as an increase of the basal $\mathrm{sCr}$ levels by $50 \%$ or $0.5 \mathrm{mg} / \mathrm{dL}$ within $48-72$ hours after contrast agent exposure.

Echocardiography was done on the first day at the CCU. Each patient received dual antiplatelet therapy. Patients receiving angiotensin converting enzyme inhibitors, statins, and infusion of nitrate and intravenous saline within the first 48 hours of treatment at the CCU were considered positive for these treatments.

CAVI and ABI were measured using the VaSera VS-1000 (Fukuda-Denshi Company, Ltd, Tokyo, Japan) which is a portable machine. We evaluated $C A V I<8.0$ as normal, 8.0-9.0 as borderline, and $>9.0$ as possible AS.

SPSS 24.0 computer statistics package software was employed. Categorical variables were represented as either numbers or percentages, and continuous variables were represented as mean \pm standard deviation. A Chi-square test and Fisher's exact test were used for comparing categorical variables. For comparing continuous variables; first, parameters were checked for normality of distribution by using the
Kolmogorov-Smirnov test. An independent sample t-test was used for comparing normally distributed data between the two groups. The variables that reached statistical significance in the analyses were evaluated by binary logistic regression analysis; or determined in binary logistic regression analysis is given at $95 \%$. For comparing the data with a normal distribution, $p<0.05$ was considered statistically significant.

\section{RESULTS}

After exclusion of 320 patients (according to the exclusion criteria of this study) from a total of 1,520 ACS patients, the incidence of CIN was 5.5\%. In the CIN group, mean age was higher $(69.9 \pm 11.8$ vs. $62.1 \pm 11.9$ years, $p<0.001)$, and EF was lower $(44.5 \pm 10.6 \%$ vs. $49.3 \pm 9.8 \%, p=0.011)$ than in the non-CIN group. In the CIN group, history of coronary artery bypass grafting (CABG) was more frequent, and rate of intravenous saline use was higher in the first 48 hours after the procedure due to the possible risk of developing CIN (Table I).

There was no significant difference between the two groups in terms of sex, body mass index and diabetes mellitus (DM) prevalence.

The mean syntax score $(15.2 \pm 8.4$ vs. $10.3 \pm 6.9, p=$ 0.001 ) and the total number of stents implanted during the percutaneous procedure were higher in the CIN group than in the non-CIN group (Table II). As expected, femoral puncture rate, duration of angiographic procedure and total amount of contrast used in the procedure were significantly higher in the CIN group. 
Table II: Procedural characteristics.

\begin{tabular}{|c|c|c|c|}
\hline & $\begin{array}{c}\text { CIN Group, } \\
\mathrm{n}=66(52.4 \%)\end{array}$ & $\begin{array}{l}\text { Non-CIN Group, } \\
n=60(47.6 \%)\end{array}$ & $\mathbf{p}$ \\
\hline $\begin{array}{l}\text { MI type, n (\%) } \\
\text { Anterior } \\
\text { Inferior } \\
\text { NSTEMI } \\
\text { USAP }\end{array}$ & $\begin{array}{l}15(22.7) \\
17(25.8) \\
32(48.5) \\
2(3.0)\end{array}$ & $\begin{array}{l}13(21.7) \\
14(23.3) \\
31(51.7) \\
2(3.3)\end{array}$ & $\begin{array}{c}0.886 \\
0.752 \\
0.721 \\
>0.999\end{array}$ \\
\hline $\begin{array}{l}\text { Culprit artery, } \mathrm{n}(\%) \\
\text { LAD } \\
\text { CX } \\
\text { RCA } \\
\text { Any side branch } \\
\text { LMCA }\end{array}$ & $\begin{array}{l}25(37.9) \\
13(19.7) \\
20(30.3) \\
7(10.6) \\
1(1.5)\end{array}$ & $\begin{array}{c}24(40.0) \\
12(20.0) \\
17(28.3) \\
5(8.3) \\
2(3.3)\end{array}$ & $\begin{array}{l}0.807 \\
0.966 \\
0.808 \\
0.664 \\
0.605\end{array}$ \\
\hline Spontaneous recanalized, $\mathrm{n}(\%)$ & $30(45.5)$ & $34(56.7)$ & 0.209 \\
\hline Syntax score & $15.2 \pm 8.4$ & $10.3 \pm 6.9$ & 0.001 \\
\hline $\begin{array}{l}\text { Access site, } \mathrm{n}(\%) \\
\text { Radial } \\
\text { Femoral }\end{array}$ & $\begin{array}{l}28(42.4) \\
38(57.6)\end{array}$ & $\begin{array}{l}45(75.0) \\
15(25.0)\end{array}$ & $<0.001$ \\
\hline Procedure duration, minutes & $43.5 \pm 23.3$ & $28.3 \pm 14.1$ & $<0.001$ \\
\hline Contrast volume, $\mathrm{mL}$ & $205.9 \pm 95.3$ & $160.3 \pm 81.2$ & 0.005 \\
\hline Stent implantation, n (\%) & $52(78.8)$ & $40(66.7)$ & 0.126 \\
\hline Total implanted stent per a patient, $\mathrm{n}$ & $1.06 \pm 0.8$ & $0.75 \pm 0.6$ & 0.013 \\
\hline $\begin{array}{l}\text { Revascularized vessels, } n(\%) \\
1 \text { vessel } \\
2 \text { vessels } \\
3 \text { or more vessels }\end{array}$ & $\begin{array}{l}25(37.9) \\
21(31.8) \\
15(22.7)\end{array}$ & $\begin{array}{l}29(48.3) \\
17(28.3) \\
8(13.3)\end{array}$ & $\begin{array}{l}0.236 \\
0.670 \\
0.173\end{array}$ \\
\hline Bifurcation stenting, $\mathrm{n}(\%)$ & $8(12.1)$ & $12(20.0)$ & 0.227 \\
\hline Only balloon angioplasty, $\mathrm{n}(\%)$ & $6(9.1)$ & $6(10.0)$ & 0.862 \\
\hline Failed intervention, $\mathrm{n}(\%)$ & $2(3.0)$ & $0(0.0)$ & 0.497 \\
\hline Recurrent angioplasty during hospitalization, n (\%) & $6(9.1)$ & $1(1.7)$ & 0.118 \\
\hline Non-compliant balloon use, $\mathrm{n}(\%)$ & $20(30.3)$ & $11(18.3)$ & 0.119 \\
\hline No-reflow phenomenon, $\mathrm{n}(\%)$ & $8(12.1)$ & $3(5.0)$ & 0.157 \\
\hline Scopy duration, minutes & $196.1 \pm 514.5$ & $150.3 \pm 308.6$ & 0.551 \\
\hline X-ray exposure, mGy & $96.1 \pm 243.5$ & $96.1 \pm 243.5$ & 0.931 \\
\hline
\end{tabular}

Table III: CAVI results and in-hospital outcomes.

\begin{tabular}{|c|c|c|c|}
\hline & $\begin{array}{c}\text { CIN Group, } \\
\mathrm{n}=66(52.4 \%)\end{array}$ & $\begin{array}{c}\text { Non-CIN Group, } n=60 \\
(47.6 \%)\end{array}$ & $\mathbf{p}$ \\
\hline Right side-CAVI & $9.6 \pm 1.3$ & $8.9 \pm 1.3$ & 0.006 \\
\hline Left side-CAVI & $9.6 \pm 1.3$ & $8.9 \pm 1.4$ & 0.007 \\
\hline Right side- $A B I$ & $1.1 \pm 0.6$ & $1.1 \pm 0.1$ & 0.957 \\
\hline Left side-ABI & $1.3 \pm 1.6$ & $1.1 \pm 0.1$ & 0.275 \\
\hline Access site complications, n (\%) & $4(6.1)$ & $2(3.3)$ & 0.682 \\
\hline Bradyarrhythmia, n (\%) & $2(3.0)$ & $1(1.7)$ & $>0.999$ \\
\hline GFR at admission, $\mathrm{mL} / \mathrm{min} / 1.73 \mathrm{~m}^{2}$ & $60.3 \pm 23.3$ & $87.0 \pm 21.5$ & $<0.001$ \\
\hline Control urea, mg/dL & $95.0 \pm 35.9$ & $42.6 \pm 16.7$ & $<0.001$ \\
\hline Control creatinine, $\mathrm{mg} / \mathrm{dL}$ & $2.3 \pm 1.1$ & $0.9 \pm 0.2$ & $<0.001$ \\
\hline Control GFR, mL/min/1.73m2 & $32.7 \pm 21.0$ & $84.0 \pm 21.9$ & $<0.001$ \\
\hline Mortality, n (\%) & $8(12.1)$ & $2(3.3)$ & 0.099 \\
\hline
\end{tabular}

As Table III shows, CAVI values of both left and right side, which are indicative of AS, were significantly higher in the CIN group. Although mortality was higher in the CIN group numerically, it did not reach statistical significance $(p=0.099)$.

The mean age of patients with CAVI $>9.0$ was higher due to the increasing arterial stiffness by age (Table IV). There was no statisti- cally significant mortality increase in myocardial infarction patients with CAVI >9.0 ( $p=0.088)$.

The effect of age, R-CAVI, L-CAVI on CIN development analysed using binary logistic regression analysis, revealed that the age factor $(O R=1.05,95 \% \mathrm{Cl}, 1.016$ to $1.086,(p=0.004)$ increased the risk of CIN by 1.05 . 


\begin{tabular}{|c|c|c|c|c|c|c|}
\hline & $\begin{array}{c}\text { R-CAVI>9 } \\
n=76 \\
60.3 \%\end{array}$ & $\begin{array}{c}\text { R-CAVI }<9 \\
n=50 \\
39.7 \%\end{array}$ & $\mathbf{p}$ & $\begin{array}{c}\text { L-CAVI>9 } \\
n=78 \\
61.9 \%\end{array}$ & $\begin{array}{c}\text { L-CAVI<9 } \\
n=48 \\
38.1 \%\end{array}$ & $\mathbf{p}$ \\
\hline Age, years & $68.9 \pm 11.6$ & $62 \pm 12.5$ & 0.002 & $68.1 \pm 11.6$ & $63 \pm 13.2$ & 0.023 \\
\hline BMI, $\mathrm{kg} / \mathrm{m}^{2}$ & $27.4 \pm 3.7$ & $28.2 \pm 3.9$ & 0.227 & $27.4 \pm 3.7$ & $28.2 \pm 3.9$ & 0.253 \\
\hline GFR & $68.4 \pm 24.7$ & $80.0 \pm 26.7$ & 0.014 & $69.2 \pm 24.6$ & $79.2 \pm 27.6$ & 0.037 \\
\hline HT, n (\%) & $50(65.8)$ & $32(64.0)$ & 0.837 & $50(64.1)$ & $32(66.7)$ & 0.769 \\
\hline $\mathrm{DM}, \mathrm{n}(\%)$ & $35(46.1)$ & $19(38.0)$ & 0.372 & $39(50.0)$ & $15(31.3)$ & 0.039 \\
\hline $\mathrm{HL}, \mathrm{n}(\%)$ & $6(7.9)$ & $2(4.0)$ & 0.476 & $6(7.7)$ & $2(4.2)$ & 0.709 \\
\hline CAD, n (\%) & $26(34.2)$ & $15(30.0)$ & 0.622 & $27(34.6)$ & $14(29.2)$ & 0.526 \\
\hline Current smoker, n (\%) & $23(30.3)$ & $21(42.0)$ & 0.176 & $23(29.5)$ & $21(43.8)$ & 0.103 \\
\hline $\mathrm{EF}, \%$ & $45.5 \pm 10.6$ & $48.8 \pm 9.9$ & 0.078 & $45.3 \pm 11.2$ & $49.1 \pm 8.6$ & 0.048 \\
\hline Mortality, n (\%) & $8(10.5)$ & $2(4.0)$ & 0.313 & $9(11.5)$ & $1(2.1)$ & 0.088 \\
\hline
\end{tabular}

\section{DISCUSSION}

In this study, the CAVI of CIN patients was higher than the CAVI of non-CIN patients $(p=0.006)$. Ucar et al. determined that increased aortic stiffness, measured by PWV, predicted $\mathrm{CIN} .{ }^{5} \mathrm{CAVI}$, a superior AS assessment method, was used rather than PWV because it is not affected by systolic and diastolic blood pressure. ${ }^{2}$ And our patient population was ACS patients, not stable CAD.

AS is known to be an indicator of arteriosclerosis and is associated with cardiovascular events. ${ }^{6} \mathrm{CAVI}$ has been shown to be a predictor for $\mathrm{CAD}^{7}$ and is also high in patients with other risk factors such as hypertension, DM and dyslipidemia. ${ }^{8,9}$ Arterial stiffness may be a determinant of sudden cardiac death. ${ }^{10}$ Possible long term results of arterial stiffness include left ventricular hypertrophy, endocardial predisposition to arrhythmia, increased afterload and baroreceptor dysfunction. ${ }^{11,12}$

$\mathrm{CIN}$ is an important cause of iatrogenic renal dysfunction that increases health cost, hospitalisation, morbidity and mortality. ${ }^{5}$ The mechanism of CIN development is vasoconstriction, tubular obstruction and oxidation injury. ${ }^{13}$ The contrast agent increases tubular viscosity and pressure, leading to decreased urine flow and GFR, resulting in increased interstitial pressure and renal retention, leading in turn to pathological renal damage. ${ }^{4}$

AS is associated with renin-angiotensin-aldosterone system (RAAS) activation, increased vascular calcification, inflammation, and endothelial dysfunction. ${ }^{14,15}$ Endothelin, angiotensin II, aldosterone and nitric oxide play a role in the development of AS as well as in the pathophysiology of $\mathrm{CIN} .{ }^{16,17}$ Increased arterial stiffness reduces the impedance mismatch between the central and peripheral arteries. This disrupts the pressure buffering ability of the arteries, leading to a high pulsatile pressure, increased peripheral microcirculation and vascular damage. ${ }^{18}$ This mechanism may explain the increased risk of developing CIN in AS with renal arteriole damage due to high pulsatile pressure. ${ }^{19}$ In summary, the cause of renal injury in AS can be explained as barotrauma of the stiff vascular system on the glomeruli. ${ }^{20}$
In this study, similar to the results of previous studies, duration of angiographic procedure, contrast agent dose, syntax score, and femoral puncture were found to be associated with $\mathrm{CIN}^{21,22}$ Also, CIN development was more frequent in patients with lower EF because of decreased cardiac output $(p=0.011)$.

In this patient group, the effect of age, right side CAVI (RCAVI) and left side (L-CAVI) independent factors on CIN development was analysed using binary logistic regression. This revealed that the age factor $(O R=1.05,95 \% \mathrm{Cl}, 1.016$ to $1.086, p=0.004$ ) increased the risk of CIN by $11 \%$. No predictive statistical effect of R-CAVI and L-CAVI on CIN development was detected.

The limitations of this study were that it was performed with a single-centre and low population. Multicentre, prospective future studies in a high population may shed light on the relationship between AS and CIN, and new therapies to prevent CIN development.

\section{CONCLUSION}

The frequency of CIN development increases in AS due to RAAS activation, vascular calcification and barotrauma in the glomeruli. The relationship between $\mathrm{CIN}$, (an important iatrogenic complication after ACS that increases morbidity and mortality) and AS has been evaluated and found significant by CAVI, which is independent of blood pressure change. Not only CAVI, there are many factors which may impact on results including, low EF, low GFR. Care should be taken to prevent the development of CIN, especially in patients with older age and lower GFR, in whom AS is more common.

\section{PATIENTS' CONSENT:}

Informed consents were obtained from all participants.

\section{CONFLICT OF INTEREST:}

All authors declared no conflict of interest.

\section{AUTHORS' CONTRIBUTION:}

SŞ: Contributed to design article, and authored the manuscript.

EA: Revised the manuscript, statistical analysis, final review. MMNA: Data collection, writing, drafting of the work. 
ÇA, EE: Contributed to design article, collected data.

SY: Contributed to design article, writing, literature review and approved the final manuscript.

\section{REFERENCES}

1. Shirai K, Utino J, Otsuka KM. A novel blood pressure-independent arterial wall stiffness parameter; cardio-ankle vascular index (CAVI). J Atheroscler Thromb 2006; 13(2): 101-7. doi: 10.5551/jat.13.101.

2. Takaki A, Ogawa H, Wakeyama T, Iwami T, Kimura M, Hadano $Y$ et al. Cardio-ankle vascular index is superior to brachial-ankle pulse wave velocity as an index of arterial stiffness. Hypertens Res 2008; 31(7):1347-55. doi: 10. 1291/hypres. 31.1347.

3. Sun CK. Cardio-ankle vascular index (CAVI) as an indicator of arterial stiffness. Integr Blood Press Control 2013; 6: 27-38. doi: 10.2147/IBPC.S34423.

4. Mamoulakis C, Tsarouhas K, Fragkiadoulaki I, Heretis I, Wilks MF, Spandidos DA, et al. Contrast-induced nephropathy: Basic concepts, pathophysiological implications and prevention strategies. Pharmacol Ther 2017; 180:99-112. doi: 10.1016/j. pharmthera.2017.06.009.

5. Ucar H, Gur M, Yıldırım A, Börekçi A, Gözükara MY, Seker T, et al. Increased aortic stiffness predicts contrast-induced nephropathy in patients with stable coronary artery disease undergoing percutaneous coronary intervention. Angiology 2014; 65(9):806-11. doi: 10.1177/00033 19713504126.

6. Shirai K, Suzuki K, Tsuda S, Shimizu K, Takata M, Yamamoto $T$, et al. Comparison of Cardio-ankle vascular index and CAVI in large healthy and hypertensive populations. J Atheroscler Thromb 2019; 26(7): 603-615. doi: 10.5551/jat.48314.

7. Otsuka K, Fukuda S, Shimada K, Suzuki K, Nakanishi K, Yoshiyama $M$, et al. Serial assessment of arterial stiffness by cardio-ankle vascular index for prediction of future cardiovascular events in patients with coronary artery disease. Hypertens Res 2014; 37(11):1014-20. doi: 10.1038/ hr.2014.116.

8. Okura T, Watanabe S, Kurata M, Manabe S, Koresawa M, Irita J, et al. Relationship between cardio-ankle vascular index (CAVI) and carotid atherosclerosis in patients with essential hypertension. Hypertens Res 2007; 30(4):335-40. doi: 10.1291/hypres.30.335.

9. Ibata J, Sasaki H, Kakimoto T, Matsuno S, Nakatani M, Kobayashi $\mathrm{M}$, et al. Cardio-ankle vascular index measures arterial wall stiffness independent of blood pressure. Diabetes Res Clin Pract 2008; 80(2):265-70. doi: 10.1016/j.diabres.2007.12.016.

10. Townsend RR. Arterial stiffness in CKD: A review. Am J Kidney Dis 2019; 73(2):240-7. doi: 10.1053/j.ajkd.2018. 04.005 .
11. Kim D, Shim CY, Hong GR, Park S, Cho I, Chang HJ, et al. Differences in left ventricular functional adaptation to arterial stiffness and neurohormonal activation in patients with hypertension: A study with twodimensional layer-specific speckle tracking echocardiography. Clin Hypertens 2017; 23:21. doi: 10.1186/s40885-017-0078-9.

12. Okada Y, Galbreath MM, Shibata S, Jarvis SS, VanGundy TB, Meier RL, et al. Relationship between sympathetic baroreflex sensitivity and arterial stiffness in elderly men and women. Hypertension 2012; 59(1):98-104. doi: 10.1161/HYPERTENSIONAHA.111.176560.

13. McCullough PA. Contrast-induced acute kidney injury. J Am Coll Cardiol 2008; 51(15): 1419-28.

14. Wagenseil JE, Mecham RP. Elastin in large artery stiffness and hypertension. J Cardiovasc Transl Res 2012; 5(3): 264-73. doi: 10.1007/s12265-012-9349-8.

15. Toussaint ND, Lau KK, Strauss BJ, Polkinghorne KR, Kerr PG. Associations between vascular calcification, arterial stiffness and bone mineral density in chronic kidney disease. Nephrol Dial Transplant 2008; 23(2):586-93. doi: 10.1093/ndt/gfm660.

16. Zieman SJ, Melenovsky V, Kass DA. Mechanisms, pathophysiology, and therapy of arterial stiffness. Arterioscler Thromb Vasc Biol 2005; 25(5):932-43. doi: 10.1161/01. ATV.0000160548.78317.29.

17. Thomsen HS, Morcos SK. Contrast media and the kidney: European society of urogenital radiology (ESUR) guidelines. $\mathrm{Br} J$ Radiol 2003; 76(908):513-8. doi: 10.1259/bjr/ 26964464.

18. Coutinho T, Turner ST, Kullo IJ. Aortic pulse wave velocity is associated with measures of subclinical target organ damage. JACC Cardiovasc Imaging 2011; 4(7):754-61. doi: 10.1016/j.jcmg.2011.04.011.

19. O'Rourke MF, Safar ME. Relationship between aortic stiffening and microvascular disease in brain and kidney: cause and logic of therapy. Hypertension 2005; 46(1): 200-4. doi: 10.1161/01.HYP.0000168052.00426.65.

20. Greenwood SA, Mangahis E, Castle AM, Wang J, Campbell J, Deshpande $\mathrm{R}$, et al. Arterial stiffness is a predictor for acute kidney injury following coronary artery bypass graft surgery. J Cardiothorac Surg 2019; 14(1):51. doi: 10.1186/s13019-019-0873-3.

21. Mehran R, Aymong ED, Nikolsky E. A simple risk score for prediction of contrast-induced nephropathy after percutaneous coronary intervention: Development and initial validation. J Am Coll Cardiol 2004; 44(7):1393-9. doi: 10.1016/j.jacc.2004.06.068.

22. Feldkamp T, Luedemann M, Spehlmann ME, Wolf SF, Gaensbacher J, Schulte $K$, et al. Radial access protects from contrast media induced nephropathy after cardiac catheterisation procedures. Clin Res Cardiol 2018; 107(2): 148-57. doi: 10.1007/s00392-017-1166-2. 